\title{
Invasion dynamics of an introduced squirrel in Argentina
}

\author{
M. Laura Guichón ${ }^{1,2}$ and C. Patrick Doncaster ${ }^{2}$ \\ ${ }^{1}$ Departamento de Ciencias Básicas, Universidad Nacional de Luján, Rutas 5 y 7 (6700), \\ Buenos Aires, Argentina \\ ${ }^{2}$ School of Biological Sciences, University of Southampton, Southampton SO16 7PX, UK
}

Address for correspondence:

M. Laura Guichón

Grupo de Estudios en Ecología de Mamíferos

Departamento de Ciencias Básicas

Universidad Nacional de Luján

Rutas 5 y 7 - (6700) Luján

Buenos Aires - Argentina

E-mail: mlguichon@unlu.edu.ar

FAX: 542323425795 
Abstract

Biological invasions are one of the major threats to both ecosystem and

3 economic functioning. Their management typically involves culling of the pest or

4 removal of its habitat. The Asiatic Red-Bellied Beautiful Squirrel Callosciurus

5 erythraeus is the first known introduction of a squirrel into South America. It

6 established from five releases in 1973, using exotic trees to spread through

7 Argentinean Pampas. It now causes substantial economic damage in agricultural and

8 urban areas across $>680 \mathrm{~km}^{2}$, and its continued spread threatens indigenous species.

9 We developed a spatially explicit model of the invasion for the likely range of life-

10 history parameters, matched against empirical data on patch occupancy in 2004. The

11 two best-fitting models suggest the current population to be on the cusp of an

12 explosive expansion. These models were used to predict future trends under

13 alternative scenarios of strategic culling or habitat removal aimed at slowing the

14 spread. The predictions for 18 years into the future were that (i) the present lack of

15 systematic management will lead to a 5-fold increase in area of occupancy, (ii)

16 removal of habitat down to half carrying capacity will thin the population but

17 accelerate its spread, (iii) 10 yrs of culling above the maximum sustainable yield

18 (MSY) will precipitate declines in abundance and patch occupancy towards

19 extinction, but with immediate recovery upon cessation of the cull. We recommend

20 continuous culling above the MSY in priority patches, aimed at slowing arrival to

21 valuable conservation areas. This study demonstrates the need for prompt action to

22 terminate invasions before they establish. The squirrel invasion is now irreversible

23 after 30 years of slow spread across fragmented habitat. Although culling requires

24 public awareness campaigns and sustained governmental commitment, it is now the

25 best feasible strategy for managing this invasion. 


\section{Introduction}

Biological invasions are now considered one of the major threats to biodiversity

3 and ecosystem functioning, together with habitat degradation (Mack et al. 2002).

4 Although exotic species are key components of the economies of several countries

5 (e.g., most crops), they can provoke huge economic losses when they escape human

6 control (e.g., many agricultural pests; Wittenberg and Cock 2001). The problem of

7 biological invasions has long been recognised (Elton 1958) but concern about exotics

8 has increased over the last decade. Recent studies have provided new evidence of the

9 complexity of invasion dynamics and the interdisciplinary approach needed to inform

10 management plans for preventing or mitigating negative impacts (Mack et al. 2002,

11 Grosholz 2005).

12 Ecological models can provide valuable insight into the process of biological

13 invasions, both for predicting the direction of colonisation and for exploring the

14 consequences of alternative management options. Spatially-explicit population

15 models (SEPMs) present a powerful tool in this context because of their capacity to

16 incorporate the complexity of real-world landscapes in their predictions of spatial

17 distribution, abundance, and viability of populations (Dunning et al. 2006). SEPMs

18 have been applied mainly to predictions of population viability for endangered or

19 harvested species (e.g., see examples in Akçakaya 2000 and Akçakaya et al. 2004).

20 The same approach has enormous potential for modelling the new environment of an

21 invader in terms of corridors and barriers to dispersal and suitable habitat for

22 reproduction, to predict its future distribution, quantify environmental impacts,

23 compare alternative management strategies, and guide new research by identifying

24 key variables that most affect the model predictions (e.g., Rushton et al. 1997, Lurz et

25 al. 2001, Tattoni et al. 2006). 
We developed a spatially explicit model to predict the spread of the Red-Bellied

2 Beautiful Squirrel Callosciurus erythraeus. This tree squirrel is native to southeast

3 Asia and was introduced to Argentina as a pet in 1970 (Aprile and Chicco 1999). By

4 1973, 2 to 5 animals had established from a single release point in the Pampas region.

5 After 31 years of slow spread, the wild population occupied a region of $680 \mathrm{~km}^{2}$

6 around the release point by 2004 (Guichón et al. 2005). This is the first known

7 introduction of a squirrel into South America. Although no systematic studies have

8 yet been conducted on the ecology of the species in Argentina, anecdotal data (Aprile

9 and Chicco 1999) and recent observations (Guichón, unpublished data) indicate that

10 its feeding and nesting habits are associated with exotic trees in commercial and

11 ornamental plantations in rural and urban areas of the pampas. This represents another

12 example of how the success of new exotics can be facilitated by human-modified

13 environments and positive interactions among introduced species (Mack et al. 2000,

14 Grosholz 2005).

15 In the Argentine Pampas, economic damage has been reported by some

16 inhabitants and local producers to fruit plantations, forestations, and electric and

17 irrigation systems. The presence of this attractively patterned species is welcomed by

18 other inhabitants, however, who regard it as a local tourist attraction given that no

19 native squirrels inhabit this region, and some of whom catch individuals to sell or

20 keep as pets (Guichón et al. 2005). Observations of predation on the nests of native

21 birds have been reported in the Pampas (Pereira et al. 2003). Studies conducted in

22 Japan, where it was first introduced in 1935, have reported high population growth

23 and adaptability to new environments, damage of plantations, garden trees, and

24 cables, and predation of native birds (Tamura et al. 1988, 1989, Azuma 1998,

25 Miyamoto et al. 2004). The species was also introduced into France in the 1970s, 
1 where it now causes damage to trees and crops (Jouanin 1992). In its native habitat, it

2 has been subjected to control actions to limit economic damage to the forestry

3 industry caused by its debarking of coniferous trees which then become infected with

4 a fungus (Lin and Yo 1981, Yo et al. 1992a).

5 The current distribution of this squirrel in Argentina lies within a highly

6 modified rural area of the Pampas region to the west of the city of Buenos Aires

7 (Guichón et al. 2005). The northerly spread is within $30 \mathrm{~km}$ of the Paraná River Delta

8 which sustains important commercial forests and unique and bio-diverse riparian

9 forests composed of both temperate and subtropical flora and fauna (Malvárez et al.

10 1999). The Otamendi Natural Reserve within this delta protects several endemic birds

11 potentially susceptible to nest predation by the Red-Bellied Squirrel. No programme

12 of proactive management has yet been developed for this population, and currently the

13 only control is sporadic lethal trapping by local producers in response to damage.

14 Proactive control actions require long-term commitment and funding from

15 government, NGOs, wildlife managers and scientists, and the local community (Mack

16 et al. 2000, Genovesi 2005), which may take several years. Some localized control

17 actions could be taken more immediately, however, to slow the invasion towards

18 critical areas, and to establish methods and test the commitment of stakeholders

19 (Bertolino and Genovesi 2003). Here we simulate alternative control scenarios as a

20 first step to evaluating the feasibility and success of both localized and region-wide

21 actions.

22 The objectives of this study are (1) to develop a spatially explicit population

23 model (SEPM) to simulate the invasion dynamics of the Red-Bellied Squirrel in the

24 Pampas region and (2) to evaluate population viability and spread under various

25 scenarios in order to recommend a management plan to slow the invasion. In 
1 particular we modelled the alternatives of harvesting and habitat removal. Local culls

2 to harvest the population above its maximum sustainable yield can potentially

3 precipitate extinction, but require sustained effort. Removing the squirrel's habitat can

4 be done in a single operation but may have a stabilising effect on the population,

5 associated with its reduced efficiency of exploiting resources (Kent et al. 2003).

6 Materials and Methods

\section{Study area}

The study area comprised $8,100 \mathrm{~km}^{2}(90 \times 90 \mathrm{~km})$ of northeastern Buenos Aires

9 Province, Argentina, centred at the liberation site of the squirrels close to the town of 10 Jáuregui in the district of Luján (343'소 $\left.59^{\circ} 11^{\prime} \mathrm{W}\right)$. Ten Red-Bellied Squirrels were

11 bought from a pet shop in Holland and introduced to Argentina in 1970. They were

12 kept caged for 3 years until 2 to 5 individuals escaped or were liberated, originating a 13 wild population. The species now principally occupies highly fragmented woodland 14 patches in rural and urban areas of the Pampas (Aprile and Chicco 1999). Native 15 grasslands of the Pampas region have been extensively modified by agriculture, 16 livestock, and urbanisation. In our study area, fruit (mainly Actinidia sp., Citrus spp., 17 Juglans spp., Prunus sp.) and timber plantations (mainly Eucalyptus spp., Populus 18 spp.) add to an arboreal vegetation comprising exotic species used as wind curtains, 19 for shade, or as ornaments in gardens and along roads, railways, and rivers (mainly 20 Ailanthus sp., Araucaria spp., Casuarina spp., Cupressus spp., Gleditsia triacanthos, 21 Ligustrum spp., Melia azedarach, Morus spp., Pinus spp., Quercus spp., Tilia spp.). 22 All of these introduced trees are used by the squirrels (Aprile and Chicco 1999, 23 Guichón et al. 2005, Guichón, unpublished data). The temperate moist climate has 
1 mean temperatures of $23.8^{\circ} \mathrm{C}$ in January and $9.1^{\circ} \mathrm{C}$ in July, and mean annual

2 precipitation of $944 \mathrm{~mm}$.

\section{The model}

We developed a spatially-explicit, stage-structured stochastic model to simulate

5 the invasion dynamics of the Red-Bellied Squirrel in the Pampas region. Given that no previous studies have been conducted on the demography of the Red-Bellied

7 Squirrel in Argentina, we took estimates of life history parameters principally from

8 published data on the squirrel in its indigenous habitat in Taiwan and in its colonised

9 range in Japan. We used the population viability analysis program RAMAS/GIS 4.00

10 (Akçakaya 2002), which is designed to link a metapopulation model with landscape

11 data from a geographical information system (GIS).

\section{$\underline{\text { Habitat data }}$}

Published data on density and home range area were used to estimate habitat suitability for the different habitat types. The lowest density of Red-Bellied Squirrels, at 2 to 3 individuals $\mathrm{ha}^{-1}$, was reported in a Taiwanese plantation of Japanese Fir (Cryptomeria japonica) (Lin and Yo 1981), whilst 5 to 7 adults ha ${ }^{-1}$ were found in temperate mixed forest in Japan and in native habitat (Tamura et al. 1989). Home range size and overlap was always larger in males than females (Tamura et al. 1989, Yo et al. 1992b). Tamura et al. $(1987,1989)$ reported mean home range sizes of females of 0.5 to 0.7 ha, which greatly overlapped with male home ranges but not with those of other females, and mean home range sizes for males of 2.2 to 3.8 ha, which greatly overlapped with both male and female home ranges. On average, 8 males overlapped each female home range (Tamura et al. 1989), leading to densities 
1 as high as 7 to 9 sexually mature squirrels $\mathrm{ha}^{-1}$. These data were used to estimate carrying capacity of the main habitat types identified in our study region. Squirrels in the Pampas region reproduce in both urban and woodland areas (Aprile and Chicco 1999, Guichón, unpublished data), as was reported for Japan (Miyamoto et al. 2004). We defined 4 types of suitable habitat (woodland, residential, suburban, and urban) in a matrix of non-suitable habitat. Woodland habitat included all forested areas, woodland patches, and wooded corridors; in the absence of more specific information, all woodlands were considered of equal quality. Residential, suburban, and urban areas differed in their increasing degree of urbanization and decreasing degree of arboreal cover. Non-suitable habitat was defined as open areas with no trees, mainly comprising arable and pasture fields and water bodies. Woodland was considered to have the highest habitat suitability, followed by residential, suburban, and urban, with non-suitable habitat receiving a zero value (Table 1). This habitat classification was used to construct a $90 \times 90-\mathrm{km}$ habitat map with a resolution of $40 \mathrm{~m}$ to encompass the current distribution of the squirrel, using GIS Idrisi 32 (Clark Labs) and ArcGIS 8.3 (Esri). With no land-cover maps available for this area, we built this habitat map by visual interpretation of a satellite image Landsat 7 TM orbit 225-084, October 2002 (licensed by PRODITEL, Universidad Nacional de Luján), and then calculated habitat values as the number of individuals that a $40 \times 40-m$ cell of each habitat type could support.

The minimum habitat suitability value below which the habitat is not suitable for reproduction and the distance that individuals travel for daily activity provide the link between the habitat map and the metapopulation model. Miyamoto et al. (2004) considered that if the distance between woods was less than $163 \mathrm{~m}$, which is the largest linear dimension of a female home range (Tamura et al. 1987), females could 
1 move among them to establish home ranges and reproduce. Lin and Yo (1981)

2 reported maximum movements of $326 \mathrm{~m}$ and $484 \mathrm{~m}$ for mature and immature

3 females, respectively; however, these distances may be an overestimate for daily

4 movements within non-contiguous wooded areas. The 'perceptual range' of a species

5 describes the maximum distance from which an animal can perceive the presence of

6 remote patches of habitat (Lima and Zollner 1996) and it becomes relevant for

7 modelling gap crossing. We assumed daily movements of $160 \mathrm{~m}$, after combining

8 published information on the use of space by the Red-Bellied Squirrel with data from

9 other sciurids (Zollner 2000: perceptual range of $120 \mathrm{~m}$ for Tamias striatus and $300 \mathrm{~m}$

10 for Sciurus carolinensis; Gurnell et al. 2002: movement between patches up to $200 \mathrm{~m}$

11 apart by S. vulgaris; Verbeylen et al. 2003: trivial range of $S$. vulgaris encompasses

12 patches separated by up to $50 \mathrm{~m}$; Selonen and Hanski 2004: fields 100-150 m wide

13 seldom traversed by Pteromys volans). The estimate of daily movements takes into

14 account the potential for squirrels to use cables, isolated trees and bushes, and high

15 vegetation on field borders when crossing open fields and rivers (personal

16 observation). Hedgerows, bushes, and isolated trees increase the connectivity of

17 fragmented forest for S. vulgaris and S. carolinensis (Fitzgibbon 1993, van Apeldoorn

18 et al. 1994, Wauters et al. 1994, Selonen and Hanski 2004). Therefore, in our habitat

19 map, nearby cells within $160 \mathrm{~m}$ with habitat suitability at least equalling the threshold

20 (i.e., woodland and urban habitat) were grouped together as a 'patch'. The group of

21 individuals occupying a discrete patch is hereafter referred to as a 'population',

22 connected through dispersal to neighbouring populations. Nearest edge-to-edge

23 distances yielded inter-patch distances. We used highways and main rivers to divide

24 patches close enough to be assigned to the same patch but that would not be easily

25 crossed by squirrels. The carrying capacity of each patch was calculated as the total 
1 habitat suitability within the patch (i.e., the sum of habitat values of woodland,

2 residential, suburban, and urban cells). The habitat is extremely fragmented because

3 of small forested patches used for shade or wind curtains in this agricultural

4 landscape. Patches with a carrying capacity $(K)<75$ individuals, were absorbed into

5 the dispersal matrix as 'stepping-stone' fragments that facilitate dispersal between

6 permanent local populations. These smaller patches accounted for only $8 \%$ of suitable

7 area and their incorporation as independent patches would have vastly inflated the

8 patch matrix without contributing substantially to the metapopulation dynamics. In

9 effect, their inclusion in the matrix of unsuitable habitat gave us a conservative

10 estimate of the expansion rate across a total of 497 suitable patches.

11 Demographic data

12 We modelled the dynamics of the population within each patch with a

13 composite age-structured Leslie matrix, with 3 age classes for each sex: juveniles in

14 their first year of life, yearlings in their second year, and adults in their third year and

15 above. We assumed that: (1) all births in the population take place in a relatively short

16 breeding period in spring, (2) the population is censused immediately before the

17 annual birth pulse, (3) no deaths occur between litters within the reproductive season,

18 and (4) the Leslie matrix applies across all populations.

19 We used mean yearly survival rates, $p_{x}$, reported by Tamura (2003) for the Red-

20 Bellied Squirrel in Japan, except for the survival rate of adults older than 3 years for

21 which we used a value of 0.3 (Table 1), influenced by Gurnell (1987) who reported

22 that patterns of survival appear similar among Holartic tree squirrels: once they have

23 achieved their second year of life, year-to-year survival is $50-70 \%$. The mean number

24 of viable offspring per individual of each age (fecundity, $F_{x}$ ) was calculated as the

25 age-specific offspring production (maternity, $m_{x}$ ) multiplied by the survival of 
1 juveniles $\left(p_{j}\right)$ (Akçakaya 2002). As in most tree squirrels (Gurnell 1987), the mating

2 system of the Red-Bellied Squirrel is promiscuous. Females care for the young, and

3 each female may mate with 4 to 11 different males while a male can mate with at least

46 females within a year (Tamura et al. 1988, 1989). In our model we assumed that

5 each male can mate with up to 6 females each year. We also assumed that all females

6 breed each year and that the sex ratio is 1:1 (Yo et al. 1992a). Females establish their

7 own home ranges when they become sexually mature at about 1 year old, and they

8 may have 1 to 3 litters per year (Tamura et al. 1988, 1989). Multiplying the mean

9 juvenile survival of 0.6 (Tamura 2003) by a litter size of 2 (from a range of $1-4$ given

10 by Tamura 1999) yields a value of 1.2 weaned juveniles per litter, which is within the

11 range estimated for the Red-Bellied Squirrel, of 1.1 to 1.4 (Tamura et al. 1988,

12 Tamura 1999). We obtained estimates of fecundity $\left(F_{x}\right)$ per year from the survival of

13 juveniles $\left(p_{j}=0.6\right)$ times the litter size (2) times the number of litters per year

14 (juveniles: 1, yearlings and adults: 2) times the sex ratio (0.5) (Table 1). The resulting

15 Leslie matrix predicted a finite rate of increase, $\lambda=1.53$ year $^{-1}$; because of uncertainty

16 in these values for the Red-Bellied Squirrel in Argentina, their influence on model

17 outputs was explored by varying these estimates by $\pm 10 \%$ (Table 1 ).

18 Antagonistic behaviours and hierarchies among both male and female Red-

19 Bellied Squirrels reportedly influence their habitat use, foraging, and reproductive

20 activities (Tamura et al. 1988, Yo et al. 1992a, 1992b). We therefore assumed density-

21 dependent population growth on all vital rates (mortality as well as fecundity) due to

22 contest competition.

23 Dispersal

24 Dispersal refers to the movement of squirrels between habitat patches. We 25 assumed that dispersal occurs annually and that dispersal rate (i.e., the proportion 
1 dispersing from a source population to a target population) was determined by: (1) the

2 distance between the source and the target populations, and (2) the age and sex of the

3 potential disperser. We modelled dispersal rate as a negative exponential function of

4 distance (Akçakaya 2002), where distances were measured between patch edges. No

5 study of dispersal distances is available for this species, and only one record of a

6 dispersal event has been reported, of over $1 \mathrm{~km}$ (Lin and Yo 1981). The mean longest

7 linear dimension of a home range in Japanese populations has been estimated to be

$8435 \mathrm{~m}$ for males and $130 \mathrm{~m}$ for females (Tamura et al. 1987), while Taiwanese

9 populations have a mean of $250 \mathrm{~m}$ (Lin and Yo 1981). A distance of $1 \mathrm{~km}$ is well

10 within the range of dispersal of Tamiasciurus hudsonicus, S. carolinensis, and S. niger

11 (Goheen et al. 2003). For S. vulgaris, dispersal distances range from 0.6 to $1.3 \mathrm{~km}$

12 (Lurz et al. 1997), up to 3.2 to $3.5 \mathrm{~km}$ (Magris and Gurnell 2002) and a maximum of 4

$13 \mathrm{~km}$ (Verbeylen et al. 2003). Pteromys volans has a mean and maximal dispersal

14 distance of 2.5 and $9 \mathrm{~km}$, respectively (Selonen and Hanski 2004). Taking into

15 account differences in body size and mode of dispersal, we assumed mean and

16 maximum dispersal distances of $1 \mathrm{~km}$ and $5 \mathrm{~km}$ respectively, and varied both

17 estimates by $50 \%$ of their value to account for uncertainty (Table 1 ). As some

18 individuals are likely to move beyond this maximum dispersal distance, model

19 predictions were intentionally conservative. We assumed that juvenile males had the

20 highest dispersal rate and that adult females had the lowest rate (Table 1) based on

21 Tamura et al. (1989) that reported male- and juvenile-biased dispersal, although they

22 observed transient squirrels of both sexes and all ages. We evaluated the effect of

23 density-dependent dispersal in population spread by varying dispersal rate in direct

24 proportion to the size of the source population (Akçakaya 2002), using an arbitrary 
1 constant of proportionality (Table 1), which results in a greater proportion of

2 individuals leaving a population at high than at low densities.

3 Stochasticity

4 Environmental stochasticity was incorporated at each time step of 1 year by

5 random sampling from lognormal distributions around the set of vital rates used to

6 project the dynamics of each population, with means taken from the Leslie matrix

7 described above and standard deviations of 5\% (Akçakaya 2000). Demographic

8 stochasticity was incorporated by sampling the numbers of survivors and dispersers

9 from a binomial distribution, and the numbers of offspring from a Poisson distribution

10 (Akçakaya 2002).

11 Validation of the model

12 We varied the following 3 input parameters to account for uncertainty

13 (Akçakaya and Sjögren-Gulve 2000): survival and fecundity rates, mean dispersal

14 distance, and maximum dispersal distance (Table 1). Three levels (low, medium, and

15 high estimates) of each parameter were tested using complete Latin square sampling

16 in the standard form, which delivers a spatially balanced design (Gomes et al. 2004)

17 suitable for identifying any interacting pairs amongst the three input variables. This

18 design yields a total of 9 parameter combinations. We explored numerous other

19 combinations in order to verify that the inputs to the balanced Latin square were

20 representative of the full set of combinations. Each model was run for 1,000

21 replications, always specifying an initial abundance of 5 squirrels (3 adult females and

$22 \quad 2$ adult males) in the patch where they were originally liberated in 1973.

23 We first modelled the spatial distribution of the squirrels over 31 years,

24 representing its spread from 1973 to 2004, in order to compare the predicted patch 
1 occupancy to that observed in field reconnaissance in 2004 (Guichón et al. 2005).

2 This comparison provided a valid test of the model inputs, because the dataset of

3 observations was independent of the one used to generate the model. Although the

4 observed data are limited to presence/absence at a single point in time, they are the

5 only available information for the species in Argentina, and provide a useful reference

6 against which to discard significant under- or overestimations of regional occupancy.

All of the patches lying within the observed distribution of squirrels in 2004

8 were classified as 'occupied', which yielded $114 \mathrm{~km}^{2}$ of occupied suitable habitat.

9 The total area predicted to be invaded after 31 years was calculated by adding up the

10 areas of the patches that had an average of at least 5 individuals at the end of the

11 simulation period. The 'simple matching coefficient' (SMC, Krebs 1999) was used to

12 measure the similarity between the observed area of distribution and the area

13 predicted to be occupied by squirrels under the different parameter combinations

14 (Rushton et al. 1997). To this end, the proportion of pixels with matching predicted

15 and observed occupancy was calculated as: $(a+b) / c$, where $a$ is the number of pixels

16 predicted and observed to be occupied (positive matches), $b$ is the number of pixels

17 predicted and observed to be unoccupied (negative matches), and $c$ is the total number

18 of pixels of suitable habitat and thus belonging to a patch (matches + mismatches).

19 Prediction of expansion and alternative management scenarios

20 The 2 models that most closely matched the observed spread of squirrels to date

21 were selected to predict the dynamics of invasion over the following 20 years (i.e.,

22 over a total simulation period of 51 years up to 2024), under different management

23 scenarios taking effect within the next 10 years. Longer simulation periods were also

24 analysed to address particular questions, such as the year of invasion of Otamendi. 
The first scenario described a continuation of the present condition of no

2 systematic management. We then simulated 2 control strategies to slow down the

3 expansion of squirrels: (1) increase mortality by removing individuals; (2) decrease

4 available resources of food and refuge by a reduction in patch carrying capacities (see

5 the Discussion for an appraisal of ways to implement these strategies). We simulated

6 the removal of squirrels for 10 consecutive years from 2008 in the form of yearly culls

7 from each population of a small amount more than the maximum sustainable yield

8 (MSY $\times 1.1$, where MSY is attained at half carrying capacity under logistic growth).

9 We simulated a reduction in available patch resources from 2008 onwards by halving

10 the carrying capacity of each patch. These management actions were modelled for

11 three areas of implementation: (1) all patches; (2) a priority area of 59 patches

12 selected on the basis of the direction of the wave of advance and of the conservation

13 value of the area beyond the front of invasion at Otamendi Natural Reserve (see

14 Results); and (3) 2 central patches selected because of their location and large size

15 (the release patch and a neighbouring patch that summed up 54\% of the invaded area

16 by 2004), where local producers would be more willing to control squirrels. Invaded

17 area is expressed as the sum of all habitats occupied by at least 5 squirrels on average.

18 Spread rate was estimated following Andow et al. (1993) from the square-root of the

19 mean $R_{i}^{2}$ where $R_{i}$ are the shortest and longest radial increases in the minimum

20 convex polygon encompassing the invaded area (Jenness 2004).

\section{Results}

The habitat suitability map shows the highly fragmented habitat occupied by the

23 Red-Bellied Squirrel in the Pampas region, with contiguous tracts only in the north-

24 eastern urbanised area (Fig. 1). The $90 \times 90-\mathrm{km}^{2}$ study area encompasses $1,117 \mathrm{~km}^{2}$ of

25 suitable habitat (14\% of total area), which partitioned into $353 \mathrm{~km}^{2}$ of woodland and 
$1764 \mathrm{~km}^{2}$ of residential, suburban, and urban areas. This suitable habitat contained 497

2 patches with $K>75$, ranging in size from 0.09 to $95 \mathrm{~km}^{2}$ and covering $1,027 \mathrm{~km}^{2}$

$3 \quad(13 \%$ of total area). All of these patches had some positive dispersal rate under the set

4 of tested models, indicating some degree of connectivity for all.

\section{$5 \quad$ Validation of the model}

6 Medium and high estimates of population growth $(\lambda)$ overestimated the area of 7 squirrel occupation after the first 31 years, in comparison to the observed distribution

8 of $114 \mathrm{~km}^{2}$ (Table 2). The congruence of predicted and observed areas was relatively

9 high for the model with low $\lambda$, regardless of dispersal distance $(\mathrm{SMC}=0.96)$. The

10 inclusion of density-dependent dispersal increased similarity between observed and

11 predicted areas of occupancy in all models (Table 2), yielding lowest differences

12 between observed and predicted occupied areas for models 2 and 3 with low $\lambda$, and

13 model 4 with medium $\lambda$. Since the predictions of models 3 and 4 fell just either side of

14 the observed area, and both had high SMCs, we used these 2 models for predicting the 15 expansion of squirrels into the future. Model 3 yielded slightly conservative projects

16 from low $\lambda$ combined with a high mean, and low maximum, dispersal distance; model

174 slightly overestimated the likely rate of spread from a higher $\lambda$ combined with low 18 mean and maximum dispersal distances.

\section{Prediction of expansion and alternative management scenarios}

In the absence of control measures, the models predicted expansion to

21 occupancy of 707 to $808 \mathrm{~km}^{2}$ of suitable habitat in the 20 years following 2004 (Table

22 3) within a total convex polygon of 3,102 to $3,308 \mathrm{~km}^{2}$. The area invaded by 2024

23 comprises $63-72 \%$ of habitat susceptible to colonisation within the $90 \times 90 \mathrm{~km}$ map,

24 including most of the available urban settlements and the forests of the Delta Region 
1 with natural and commercial afforestations (Fig. 2). In particular, the models

2 predicted invasion of the Otamendi Natural Reserve in the next 16 to 24 years (Table

3 3). Given that the predicted expansion is mainly north-easterly and Otamendi is a first

4 step into the Delta Region in this direction, we selected a priority area (see Fig. 2)

5 where urgent management actions could be conducted to slow or prevent colonisation

6 in this direction, until a long-term strategy can be undertaken with broad consensus.

7 Culling squirrels in this area was at least as effective at delaying their arrival in

8 Otamendi as culling in all patches, and more effective than culling the central area

9 which did not have any delaying effect (Table 3 ). Habitat removal to reduce $K$ only

10 shortened the time to reach Otamendi, particularly when applied in the priority area

11 (Table 3).

12 The models predicted a relatively slow expansion in occupancy during the first

13 34-37 years after liberation in 1973 and then a steep increase in the invaded area (Fig.

14 3a). This indicates that the spread of squirrels may be at the cusp of an explosive

15 expansion. The rate of spread shows a tendency to increase (Fig. 3b), though large

16 variations are observed (mean $\pm \mathrm{SD}$, model 3: $1.28 \pm 1.14 \mathrm{~km}$ per year and model 4:

$17 \quad 1.44 \pm 1.23 \mathrm{~km}$ per year).

18 The increase in abundance was rather flat for the first 20 years of exponential

19 growth, and then increased dramatically (Fig. 4). High numbers predicted by model 4

20 showed signs of an intermediate plateau 30 to 40 years into the invasion, in response

21 to density-dependent regulation within colonised patches (Fig. 3a and 4b). Culling and

22 reducing $K$ resulted in broadly similar patterns of predicted abundance, with the

23 former tending to outperform the latter (Fig. 4). Numbers of squirrels and occupancy

24 area could be significantly diminished by culling each population with a constant

25 harvest for 10 years, though populations would start to recover immediately upon 
1 interruption of the harvest (Fig. 4, note the particularly sharp reversal in fortune of the

2 'cull all' scenario when culling stops after 10 years). It would take more than 30 years

3 (model 3) or 60 years (model 4) of continuous harvest in all patches to eradicate

4 squirrels. No significant advantages result from reducing the number of squirrels in

5 central patches though concentrating efforts in a priority area would restrict

6 abundance and area of occupancy while delaying the predicted invasion of Otamendi

7 by 10 to 15 years (Table 3 ). Decreasing the carrying capacity of all or only priority

8 patches has an unwanted effect of increasing the spread rate, such that Otamendi is

9 reached before the no-action scenario (Table 3).

\section{Discussion}

11 Range expansion and squirrel numbers have grown slowly for the first 2 to 3

12 decades after liberation, but the models predict a steep increase in abundance and

13 regional distribution over coming years. The pattern of rapid growth following slow

14 establishment is typical of the exponential expansion of many introduced species

15 (Crooks and Soule 1999). This is the first attempt to predict future expansion of the

16 Red Bellied Squirrel in Argentina and we acknowledge some limitations in the

17 construction and validation of the model, mainly due to sparse life history and

18 population data for our study area. As with other studies using sparse data (e.g., Lurz

19 et al. 2001, Tattoni et al. 2006), our input parameters for models are estimated from

20 diverse sources of empirical information on behavioural and population ecology from

21 the squirrel's native and exotic ranges. The use of a Latin Square of simulations at

22 least ensures realistic orders of magnitude for the invasion dynamics of this species.

23 Density-dependent dispersal reduced predicted range expansion when

24 population rate of increase was medium and high but increased predicted spread for

25 low values, and even showed a rescue effect from extinction when lower rates were 
1 used (e.g. $\lambda=1.23$, unpublished outputs). These results are consistent with the

2 population regulating effects of density dependence (e.g., Akçakaya et al. 2007). The

3 first priority for improving model predictions should be to obtain local and seasonal

4 estimates of reproduction and survival rates in different habitat types (work in

5 progress).

One of the principal aims of this modelling approach is to make recommendations based on objective evaluation of the success of alternative control

8 actions. Management measures could be oriented towards mitigating damage,

9 restricting colonization of new areas, regulating abundance, or complete eradication.

10 The probability of achieving the desired result can be evaluated by simulating

11 population responses to different control measures. Our results show that reducing the

12 carrying capacity of the habitat would lower squirrel numbers but an unwanted

13 accelerating spread would lead to a faster colonization of a key conservation area

14 (Otamendi). Non-lethal techniques have a potentially greater efficiency than lethal

15 control, since they avoid the density-dependent consequences that can follow culling,

16 and are likely to be seen as more acceptable in welfare and ethical terms (Barr et al.

17 2002, Baker et al. 2007). Decreasing the carrying capacity of suitable patches could

18 be accomplished by reducing accessibility (e.g., place sheet metal and cones to

19 impede or reduce use of trees and cables), persistence (e.g., nest destruction), and

20 suitability of resources (e.g., pruning trees to thin canopy and reduce suitability for

21 nesting; replace trees used for food and nesting by alternative, less suitable tree

22 species). Regardless of the viability of implementing this action, however, it must be

23 rejected as a viable option because of the predicted acceleration of the invasion front.

24 In contrast, model predictions show that culling squirrels could be an effective

25 measure to restrict invasion and reduce abundance, provided it targets priority areas. 
1 Culling all patches would have the largest impact on numbers and range distribution,

2 but implementing such a vast campaign has doubtful feasibility. Culling populations

3 only in central patches could create a vacuum that would rapidly be filled by local

4 growth and dispersal from neighbouring patches. However, concentrating effort and

5 resources in the priority area would delay colonization of Otamendi. This Natural

6 Reserve would be the first step into the Paraná River Delta which hosts a unique and

7 biodiverse region of riparian forests represented by both temperate and subtropical

8 species and also important commercial forests (Malvárez et al. 1999). Removing

9 squirrels would require public awareness campaigns and long-term commitment of

10 governmental authorities. Broad public support should be achieved through a

11 communication strategy informing about the problem and addressing ethical issues,

12 particularly given the charismatic appearance of the squirrel (Barr et al. 2002,

13 Bertolino and Genovesi 2003). Additionally, an adequate legal basis is needed to

14 initiate control actions, given that local authorities refuse to implement any measure

15 until the species is declared a pest. A rapid response to new invasions is the best case

16 scenario to prevent vast invasions, when technical, financial, and logistic needs are

17 more easily achieved (Mack et al. 2000, Genovesi 2005). When control actions are

18 delayed, eradication of introduced mammals is usually not viable for financial,

19 technical, or social reasons. Actions to diminish negative effects caused by already

20 established exotic species are expensive and not always successful, as in the case of

21 attempts in the United Kingdom to control S. carolinensis in order to protect $S$.

22 vulgaris and reduce bark stripping (Sheail 1999, Huxley 2003, Lawton \& Rochford

23 2007). Nevertheless, localized intensive control of introduced mammals in selected

24 areas may help to reduce some negative effects and slower their spread (Bertolino and

25 Genovesi 2003). 
Because we seldom understand ecological systems completely, applications of models need to be flexible and management must be able to adapt to new information

3 (Lyman et al. 2002). Our assessment of the most realistic and effective long-term

4 action is to target culling in priority areas, and to mitigate damage in commercial

5 plantations through local control. It is important that all such operations are closely

6 monitored, and that the predictive models are updated with information on control

7 actions and on vital rates. With more empirical information it will be possible to carry

8 out sensitivity analyses to determine the key variables that drive expansion, which can

9 then guide the collection of future data.

\section{Acknowledgements}

We thank R. Akçakaya for helping with software specifications, L. Di Franco (PRODITEL, UNLu) for facilitating satellite imaging, F. Milesi for constructive discussions at all stages, and L. Wauters and an anonymous reviewer for their help with improving the manuscript. The study was funded by a UNESCO-L'Oréal Fellowship for young women in Life Sciences to MLG at the University of Southampton and by a Small Ecological Project Grant awarded to MLG by the British Ecological Society.

\section{References}

Akçakaya, H.R.2000. Population viability analysis with demographically and spatially structured models. - Ecological Bulletins 48: 23-38.

Akçakaya, H.R. 2002. RAMAS GIS: Linking spatial data with population viability analysis (version 4.0). - Applied Biomathematics, Setauket, New York.

Akçakaya, H.R. and Sjögren-Gulve, P. 2000. Population viability analysis in conservation planning: an overview. - Ecological Bulletins 48: 9-21. 
1 Akçakaya, H.R. et al., eds. 2004. Species conservation and management: case studies. - Oxford University Press.

Akçakaya, H.R. et al. 2007. The role of metapopulations in conservation. - In: Macdonald, D. W. and Service, K. (eds), Key topics in conservation biology. Blackwell Publishing, pp. 64-84.

Andow, D.A. et al. 1993. Spread of invading organisms: patterns of spread. - In: Kim, K.C. and McPheron, B.A. Evolution of insect pests. John Wiley and Sons, pp. 219-242.

Aprile, G. and Chicco, D. 1999. Nueva especie exótica de mamífero en la Argentina: la ardilla de vientre rojo (Callosciurus erythraeus). - Mastozoología Neotropical 6: 7-14.

Azuma, Y. 1998. Nest predation of the Japanese White-eye by a Formosan squirrel. Strix 16: 175-176.

Baker, S. et al. 2007. The nature of the beast: using biological processes in vertebrate pest management. - In: Macdonald, D. W. and Service, K. (eds), Key topics in conservation biology. Blackwell Publishing, pp. 173-185.

Barr, J.J.F. et al. 2002. Evaluation of immunocontraception as a publicly acceptable form of vertebrate pest species control: the introduced Grey Squirrel in Britain as an example. - Env. Manage. 30: 342-351.

Bertolino, S. and Genovesi, P. 2003. Spread and attempted eradication of the grey squirrel (Sciurus carolinensis) in Italy, and consequences for the red squirrel (Sciurus vulgaris) in Eurasia. - Biol. Conserv. 109: 351-358.

Corbet, G.B. and Southern, N.N., eds. 1977. The handbook of British mammals, 2nd edn. - Blackwell Scientific Publications. 
1 Crooks, J.A. and Soulé, M.E. 1999. Lag times in population explosions of invasive

2 species: causes and implications. - In: Sandlund, O.T., Schei, P.J. and Viken, A.

3 (eds), Invasive species and biodiversity management. Kluwer Academic

$4 \quad$ Publishers, pp. 103-125.

5 Dunning, J.B. et al. 2006. Species and landscape approaches to conservation. - In: Groom, M.J., Moffe, G.K. and Carrol, C.R. (eds), Principles of conservation biology, 3rd edn. Sinauer Associates Inc., pp. 419-465.

Elton, C.S. 1958. The ecology of invasions by animals and plants. - Methuen.

Fitzgibbon, C.D. 1993. The distribution of grey squirrel dreys in farm woodland: the influence of wood area, isolation and management. - J. Appl. Ecol. 30: 736-742.

Genovesi, P. 2005. Eradications of invasive alien species in Europe: a review. - Biol. Invasions 7: 127-133.

Goheen, J.R. et al. 2003. Forces structuring tree squirrel communities in landscapes fragmented by agriculture: species differences in perceptions of forest connectivity and carrying capacity. - Oikos 102: 95-103.

Gomes, C. et al. 2004. The challenge of generating spatially balanced scientific experiment designs. - Lecture note in computer science 3011: 387-394. http://www.cs.cornell.edu/gomes/SBLS.htm

Grosholz, E.D. 2005. Recent biological invasion may hasten invasional meltdown by accelerating historical introductions. - Proc. Nat. Acad. Sci. USA 12: 10881091.

Guichón, M.L. et al. 2005. Expansión poblacional de una especie introducida en la Argentina: la ardilla de vientre rojo Callosciurus erythraeus. - Mastozoología Neotropical 12: 189-197.

Gurnell, J. 1987. The natural history of squirrels. - Christopher Helm. 
1 Gurnell, J. et al. 2002. Conserving red squirrels (Sciurus vulgaris): mapping and forecasting habitat suitability using a Geographic Information Systems Approach. - Biol. Conserv. 105: 53-64.

Huxley, L. 2003. The Grey Squirrel Review. Profile of an invasive alien species. Grey squirrel (Sciurus carolinensis). - ESI Dorset.

Jenness, J. 2004. Convex hulls around points (conv_hulls_pts.avx) extension for ArcView 3.x, v. 1.2 - Jenness Enterprises. http://www.jennessent.com/arcview/convex_hulls.htm

Jouanin, C. 1992. L'écureuil à ventre rouge d'Antibes. - In : Guernieau, M. (ed.) Introductions and réintroductions des Mammiferes sauvages. Actes du XIVème colloque francophone de Mammalogie de la Société française pour l'étude et la protection des Mammifères, Orlèans/Saint Jean de Braye, pp. 227-284.

Kent, A. et al. 2003. Consequences for predators of rescue and Allee effects on prey. Ecol. Model. 162: 233-245.

Krebs, C.J. 1999. Ecological methodology, 2nd edn. - Addison-Welsey Educational Publishers Inc.

Lawton, C. and Rochford, J. 2007. The recovery of grey squirrel (Sciurus carolinensis) populations after intensive control programmes. - Biology and Environment: Proceedings of the Royal Irish Academy 107B: 19-29.

Lima, S.L. and Zollner, P.A. 1996. Towards a behavioural ecology of ecological landscapes. - Trends Ecol. Evol. 11: 131-135.

Lin, Y.S. and Yo, S.P. 1981. Population dynamics of the Red-Bellied Tree Squirrel (Callosciurus erythraeus). - Bull. Inst. Zool., Acad. Sinica 20: 31-41.

Lurz, P.W.W. et al. 1997. Effects of temporal and spatial variation in habitat quality on red squirrel dispersal behaviour. - Anim. Behav. 54: 427-435. 
1 Lurz, P.W.W. et al. 2001. Predicting grey squirrel expansion in North Italy: a spatially explicit modelling approach. - Landscape Ecol. 16: 407-420.

Lynam, T. et al. 2002. Adapting science to adaptive managers: spidergrams, belief models, and multi-agent systems modeling. - Conserv. Ecol. 5: 24.

Magris, L. and Gurnell, J. 2002. Population ecology of the red squirrel (Sciurus vulgaris) in a fragmented woodland ecosystem on the Island of Jersey, Channel Islands. - J. Zool. 256: 99-112.

Mack, R.N. et al. 2000. Biotic invasions: causes, epidemiology, global consequences, and control. - Ecol. Applic. 10: 689-710.

Malvárez, A.I. et al. 1999. Biodiversidad, uso de los recursos naturales y cambios en las islas del Delta Medio del Río Paraná (Dto. Victoria, provincia de Entre Ríos, R. Argentina). - In: Matteucci, S.D., Solbrig, O.T., Morello, J. and Halffter, G. (eds), Biodiversidad y uso de la tierra: conceptos y ejemplos de Latinoamérica. Eudeba, Buenos Aires, pp. 257-290.

Miyamoto, A. et al. 2004. Predicting habitat distribution of the alien Formosan Squirrel using logistic regression model. - Global Env. Res. 8: 13-21.

Pereira, J. et al. 2003. Mamíferos de la Reserva Natural Otamendi. - In: Haene, E. and Pereira, J. (eds), Temas de Naturaleza y Conservación 3: Fauna de Otamendi, Inventario de los animales vertebrados de la Reserva Natural Otamendi, Campana, Buenos Aires, Argentina Aves Argentinas/AOP, Buenos Aires, pp. 115-139.

Rushton, S.P. et al. 1997. Modelling the distribution of the red and grey squirrel at the landscape scale: a combined GIS and population dynamics approach. - J. Appl. Ecol. 34: 1137-1154.

Selonen, V. and Hanski, I.K. 2004. Young flying squirrels (Pteromys volans) dispersing in fragmented forests. - Behav. Ecol. 15: 564-571. 
1 Sheail, J. 1999. The grey squirrel (Sciurus carolinensis)-a UK historical perspective on a vertebrate pest species. - Journal of Environmental Management 55: 145156.

Tamura, N. 1999. Seasonal change in reproductive states of the Formosan squirrel on Izo-Oshima Island, Japan. - Mammal Study 24: 121-124.

Tamura, N. 2003. Population dynamics and expansion of the Formosan squirrel introduced to Japan. $-3^{\text {rd }}$ International Squirrel Colloquium and $7^{\text {th }}$ European Squirrel Workshop, Ford Castle.

Tamura, N. et al. 1987. Home range size of the Formosan Squirrel, Callosciurus erythraeus thaiwanensis, estimated by radio tracking. - J. Mammal. Soc. Japan 12: 69-72.

Tamura, N. et al. 1988. Dominance hierarchy and mating behavior of the Formosan Squirrel, Callosciurus erythraeus thaiwanensis. - J. Mammal. 69: 320-331.

Tamura, N. et al. 1989. Spacing and kinship in the Formosan squirrel living in different habitats. - Oecologia 79: 344-352.

Tattoni, C. et al. 2006. Modelling the expansion of a grey squirrel population: implications for squirrel control. - Biol. Invasions 8: 1605-1619.

van Apeldoorn, R.C. et al. 1994. Distribution and dynamics of the red squirrel (Sciurus vulgaris L.) in a landscape with fragmented habitat. - Landscape Ecol. 9: $227-235$.

Verbeylen, G. et al. 2003. Patch occupancy, population density and dynamics in a fragmented red squirrel Sciurus vulgaris population. - Ecography 26: 118-128.

Wauters, L. et al. 1994. Space use and dispersal of red squirrels in fragmented habitats. - Oikos 69: 140-146. 
1 Wittenberg, R. and Cock, M.J.W. (eds.). 2001. Invasive Alien Species: A Toolkit of Best Prevention and Management Practices. - CAB International.

3 Yamada, K. et al. 2004. Sindh Ibex (Capra aegagrus blythi) in Kithar National Park,

4 Pakistan: sensitivity of a habitat and population model. - In: Akçakaya, H.R.,

5 Burgman, M.A., Kindvall, O., Wood, C.C., Sjögren-Gulve, P., Hatfield, J.S. and

6 McCarthy, M.A. (eds), Species conservation and management: case studies.

$7 \quad$ Oxford University Press, pp. 469-481.

8 Yo, S.P. et al. 1992a. Population dynamics and regulation of Red-Bellied tree

9 squirrels (Callosciurus erythraeus) in Japanese Fir plantations. - Bull. Inst.

10 Zool., Acad. Sinica 31: 89-103.

11 Yo, S.P. et al. 1992b. Home range dynamics of Red-Bellied Tree Squirrels

12 (Callosciurus erythraeus) in Chitou. - Bull. Inst. Zool., Acad. Sinica 31: 199-

13211.

14 Zollner, P.A. 2000. Comparing the landscape level perceptual abilities of forest

15 sciurids in fragmented agricultural landscapes. - Landscape Ecol. 15: 523-533. 
Table 1. Parameter estimates used as model inputs (with range of values in parenthesis where applicable).

\begin{tabular}{|c|c|c|}
\hline Parameter & Classification & Value (range) \\
\hline \multirow[t]{5}{*}{ Habitat quality $(K)$} & Woodland & 8 ind.ha $^{-1}$ \\
\hline & Residential & 6 ind.ha ${ }^{-1}$ \\
\hline & Suburban & 4 ind.ha $^{-1}$ \\
\hline & Urban & 2 ind.ha ${ }^{-1}$ \\
\hline & Non-suitable & 0 ind.ha ${ }^{-1}$ \\
\hline \multirow[t]{3}{*}{ Survival rates $\left(p_{x}\right)$} & Juveniles & $0.8(0.72-0.88)$ \\
\hline & Yearlings & $0.6(0.54-0.66)$ \\
\hline & Adults & $0.3(0.27-0.30)$ \\
\hline \multirow[t]{3}{*}{ Fecundity rates $\left(F_{x}\right)$} & Juveniles & $0.6(0.54-0.66)$ \\
\hline & Yearlings & $1.2(1.08-1.32)$ \\
\hline & Adults & $1.2(1.08-1.32)$ \\
\hline Finite rate of increase $(\lambda)$ & & 1.53 year $^{-1}(1.38-1.68)$ \\
\hline Mean dispersal distances & & $1 \mathrm{~km}(0.5-1.5)$ \\
\hline Maximum dispersal distances & & $5 \mathrm{~km}(2.5-7.5)$ \\
\hline \multirow[t]{3}{*}{ Male:female relative dispersal } & Juveniles & $1.0: 0.4$ \\
\hline & Yearlings & $0.7: 0.3$ \\
\hline & Adults & $0.4: 0.2$ \\
\hline Density-dependent dispersal constant & & $0(0.001)$ \\
\hline
\end{tabular}


Table 2. Model inputs to the Latin Square design: finite rate of increase ( $\lambda$ ), mean dispersal distance (MeanDD), and maximum dispersal distance (MaxDD), predicted area of occupancy after 31 years of invasion (difference from observed occupancy of $114 \mathrm{~km}^{2}$ in 2004 in parentheses), and simple matching coefficient (SMC). The last 2 columns show predictions for models incorporating density dependent dispersal.

\begin{tabular}{|c|c|c|c|c|c|c|c|}
\hline & \multirow[b]{2}{*}{$\lambda$} & \multirow[b]{2}{*}{ MeanDD } & \multirow[b]{2}{*}{ MaxDD } & \multirow[b]{2}{*}{ Area $\left(\mathrm{km}^{2}\right)$} & \multirow[b]{2}{*}{ SMC } & \multicolumn{2}{|c|}{ Density dependent dispersal } \\
\hline & & & & & & Area $\left(\mathrm{km}^{2}\right)$ & SMC \\
\hline 1 & 1.38 & 0.5 & 7.5 & $73(-41)$ & 0.96 & $88(-26)$ & 0.97 \\
\hline 2 & & 1.0 & 5.0 & $72(-42)$ & 0.96 & $111(-3)$ & 0.96 \\
\hline 3 & & 1.5 & 2.5 & $73(-41)$ & 0.96 & $93(-21)$ & 0.98 \\
\hline 4 & 1.53 & 0.5 & 2.5 & $374(+260)$ & 0.70 & $124(+10)$ & 0.94 \\
\hline 5 & & 1.0 & 7.5 & $672(+558)$ & 0.46 & $283(+169)$ & 0.84 \\
\hline 6 & & 1.5 & 5.0 & $447(+333)$ & 0.68 & $404(+290)$ & 0.72 \\
\hline 7 & 1.68 & 0.5 & 5.0 & $804(+690)$ & 0.33 & $361(+247)$ & 0.72 \\
\hline 8 & & 1.0 & 2.5 & $825(+711)$ & 0.31 & $412(+298)$ & 0.70 \\
\hline 9 & & 1.5 & 7.5 & $934(+820)$ & 0.20 & $493(+379)$ & 0.64 \\
\hline
\end{tabular}


Table 3. Predicted expansion and abundance $( \pm$ SD) of squirrels by the year 2024, and time to reach the Otamendi Natural Reserve under alternative management scenarios.

\begin{tabular}{cccccccc}
\hline & \multicolumn{3}{c}{ Area by 2024 $\left(\mathrm{km}^{2}\right)$} & \multicolumn{2}{c}{ Abundance by 2024 } & \multicolumn{2}{c}{ Year reaches Otamendi } \\
Scenario & Area & Model 3 & Model 4 & Model 3 & Model 4 & Model 3 & Model 4 \\
\hline No control & - & 707 & 808 & $55,251(25,136)$ & $122,557(44,171)$ & 2031 & 2023 \\
Cull squirrels & all & 140 & 381 & $17,525(9854)$ & $35,086(9985)$ & 2044 & 2038 \\
& priority & 288 & 408 & $36,277(13,861)$ & $40,380(10,591)$ & 2041 & 2038 \\
& central & 707 & 810 & $45,173(24,755)$ & $121,259(42,752)$ & 2031 & 2023 \\
Reduce $K$ & all & 826 & 893 & $30,570(14,173)$ & $74,543(24,526)$ & 2024 & 2016 \\
& priority & 818 & 811 & $39,704(16,800)$ & $99,972(29,096)$ & 2021 & 2016 \\
& central & 713 & 793 & $45,712(21,811)$ & $110,861(39,299)$ & 2029 & 2023 \\
\hline
\end{tabular}


Figure 1. (a) Location of study site in Argentina, (b) square showing the study area with the release point of the squirrels in the centre $(\times)$, the area covered by the city of Buenos Aires and its large suburbs, the Lower Delta Region of the Paraná River, Otamendi Natural Reserve, and the central and priority areas used for modelling alternative management scenarios, and (c) map showing suitable habitat for squirrels (wooded habitat in black and urban habitats in grey) and the matrix of unsuitable habitat (non-forested areas in white), indicating the range expansion observed by 2004 (polygon).

Figure 2. Area of occupancy predicted under current scenario of no control by (a) model 3 and (b) model 4 in 2004 (black), 2014 (dark grey), and 2024 (light grey).

Figure 3. Model predictions under current scenario of no control: (a) range expansion since liberation of squirrels in 1973 (area estimated using the minimum convex polygon method) predicted by models 3 (dashed line) and 4 (solid line), and (b) spread rate (dots indicate new invaded area every 3 years after liberation with trend line showing predicted increase of colonisation speed) predicted by models 3 (open circles, dashed line) and 4 (black squares, solid line). Arrow indicates year 2007.

Figure 4. Predicted abundance of population by (a) model 3, and (b) and model 4 since liberation of squirrels in 1973, under alternative scenarios described in Methods (no control, black solid line; culling, dashed lines; reduce k, grey solid line). Standard deviations are not shown for graph clarity though values never reached zero, see Table 2 for SD of no control scenario. Note different scales of $y$-axes in (a) and (b). Arrows indicate year 2007. 
Figure 1 - Guichón \& Doncaster

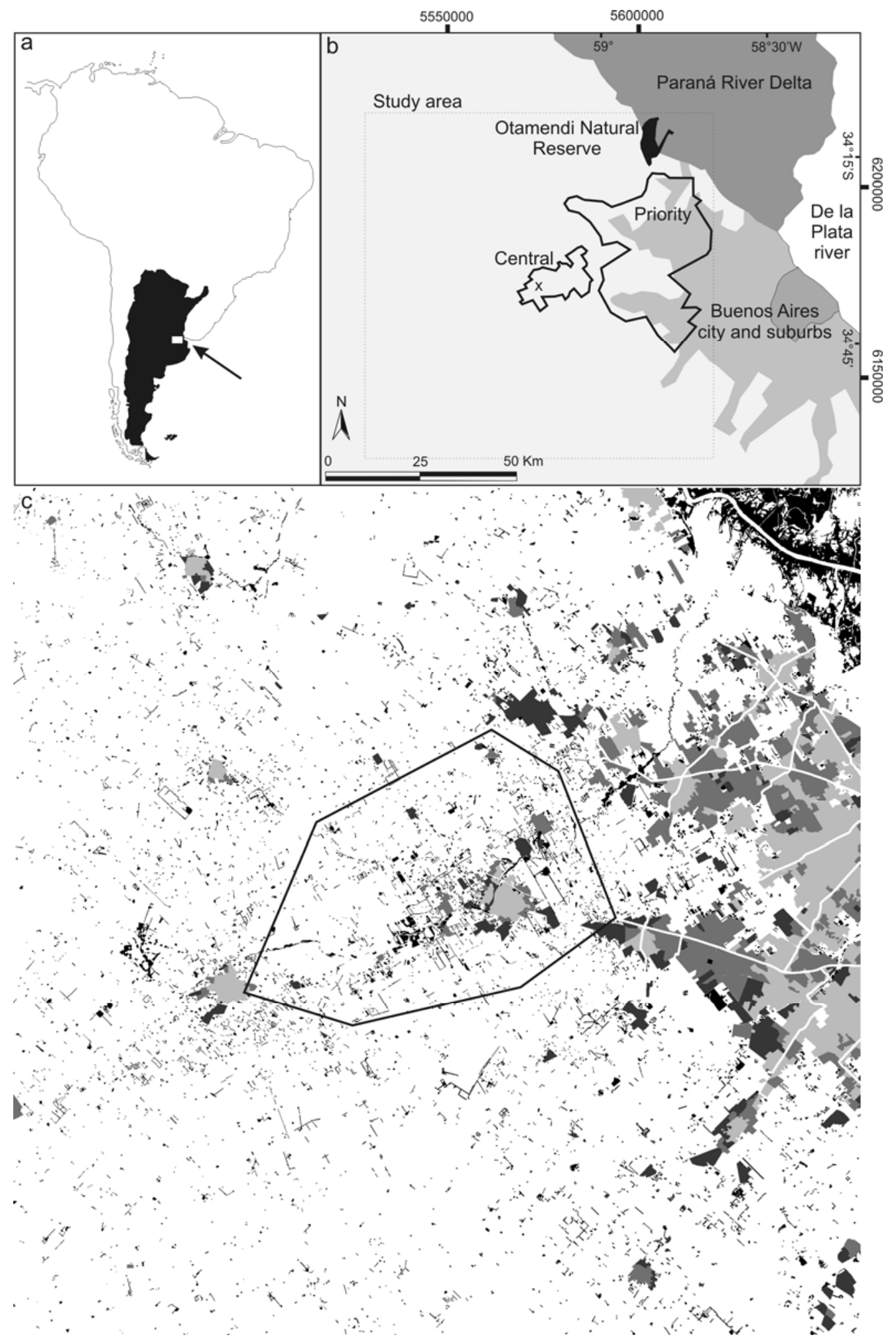


Figure 2 - Guichón \& Doncaster

a

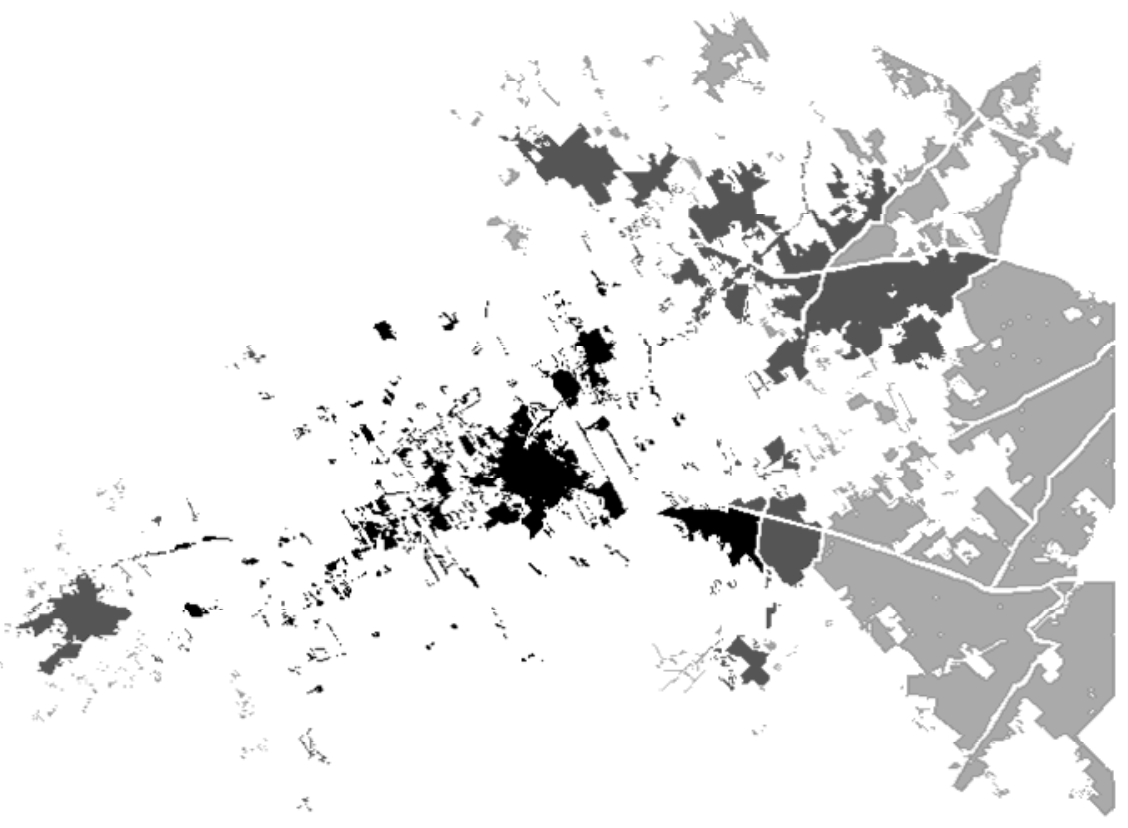

b

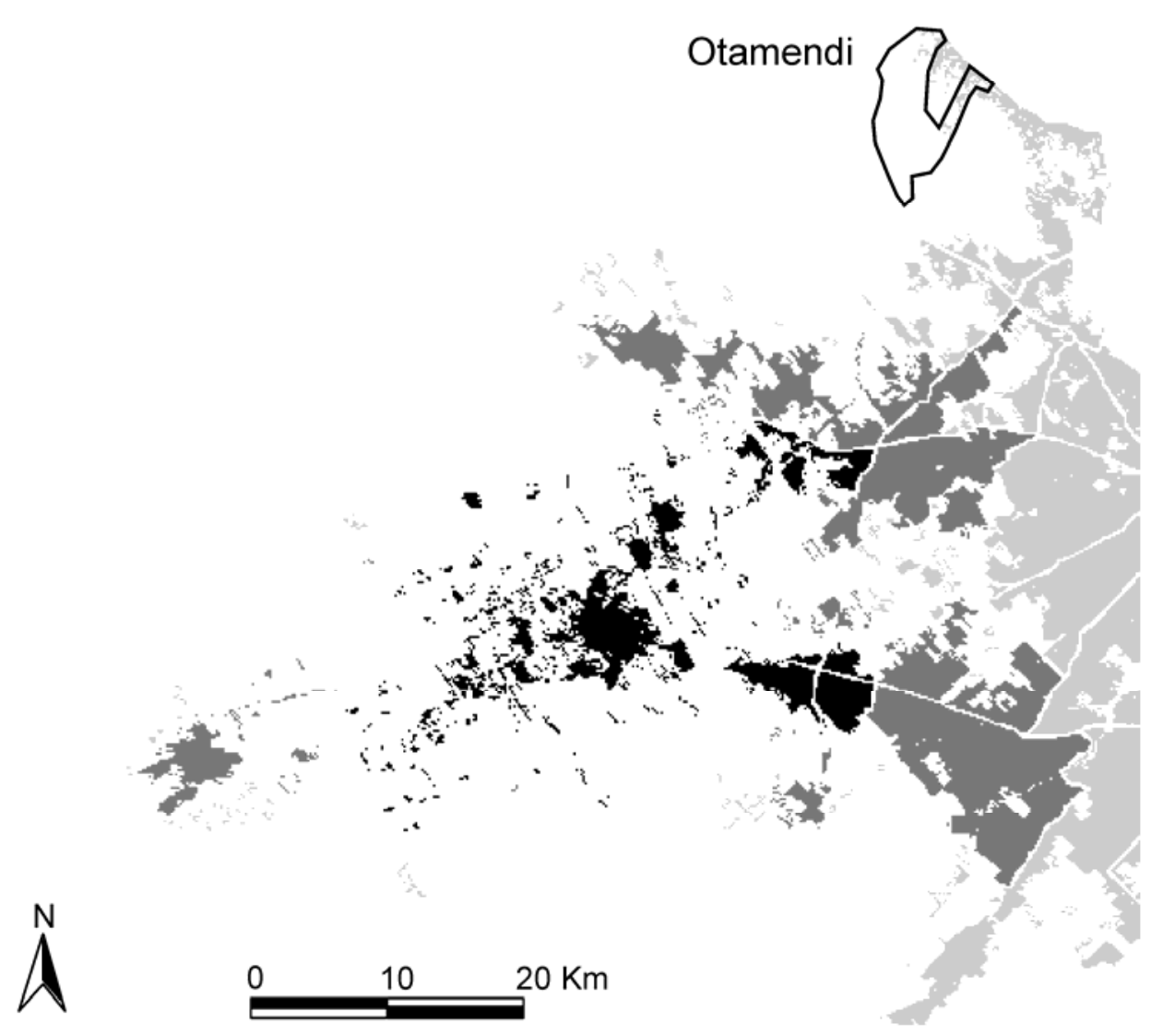


Figure 3 - Guichón \& Doncaster
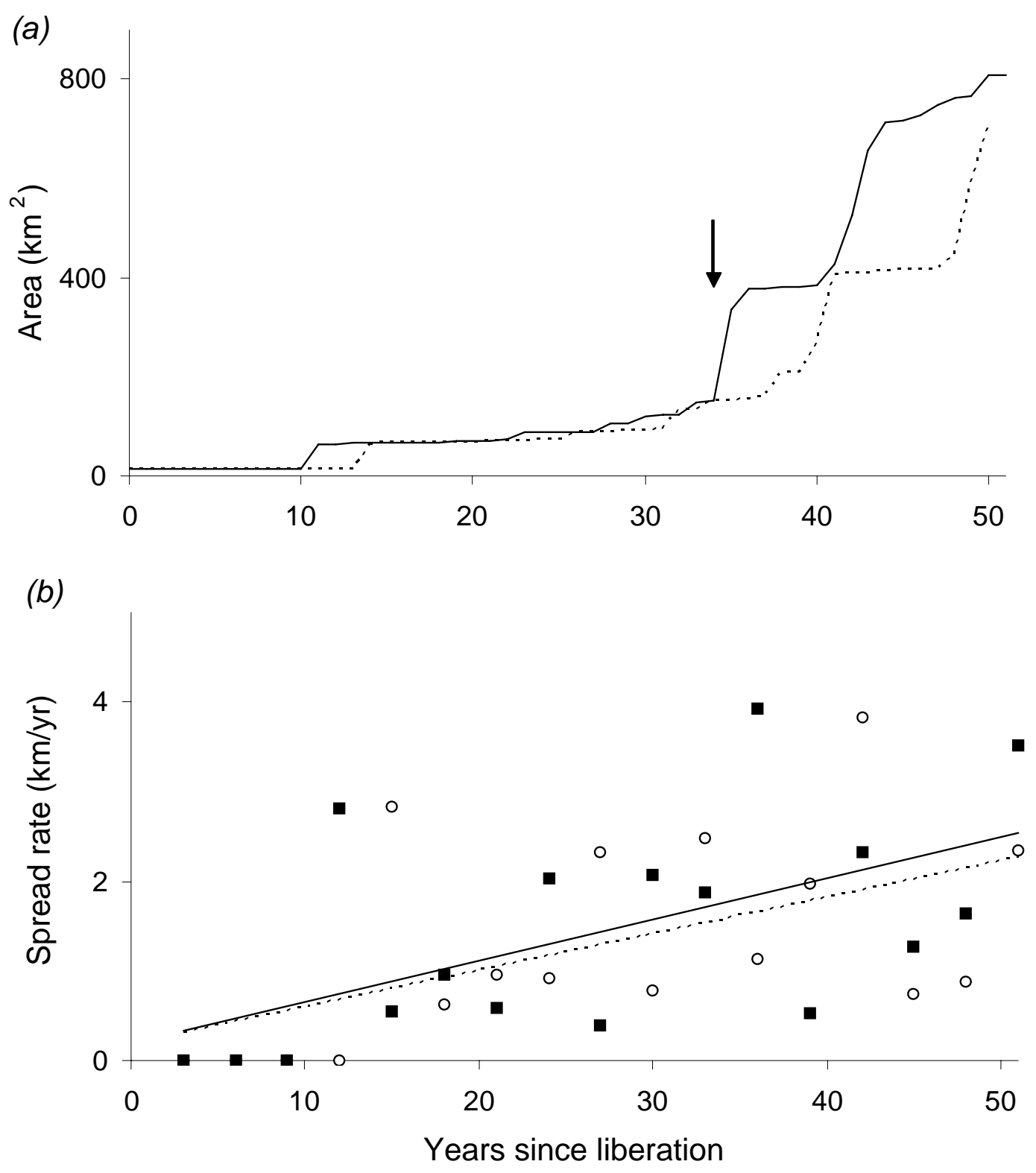
Figure 4 - Guichón \& Doncaster
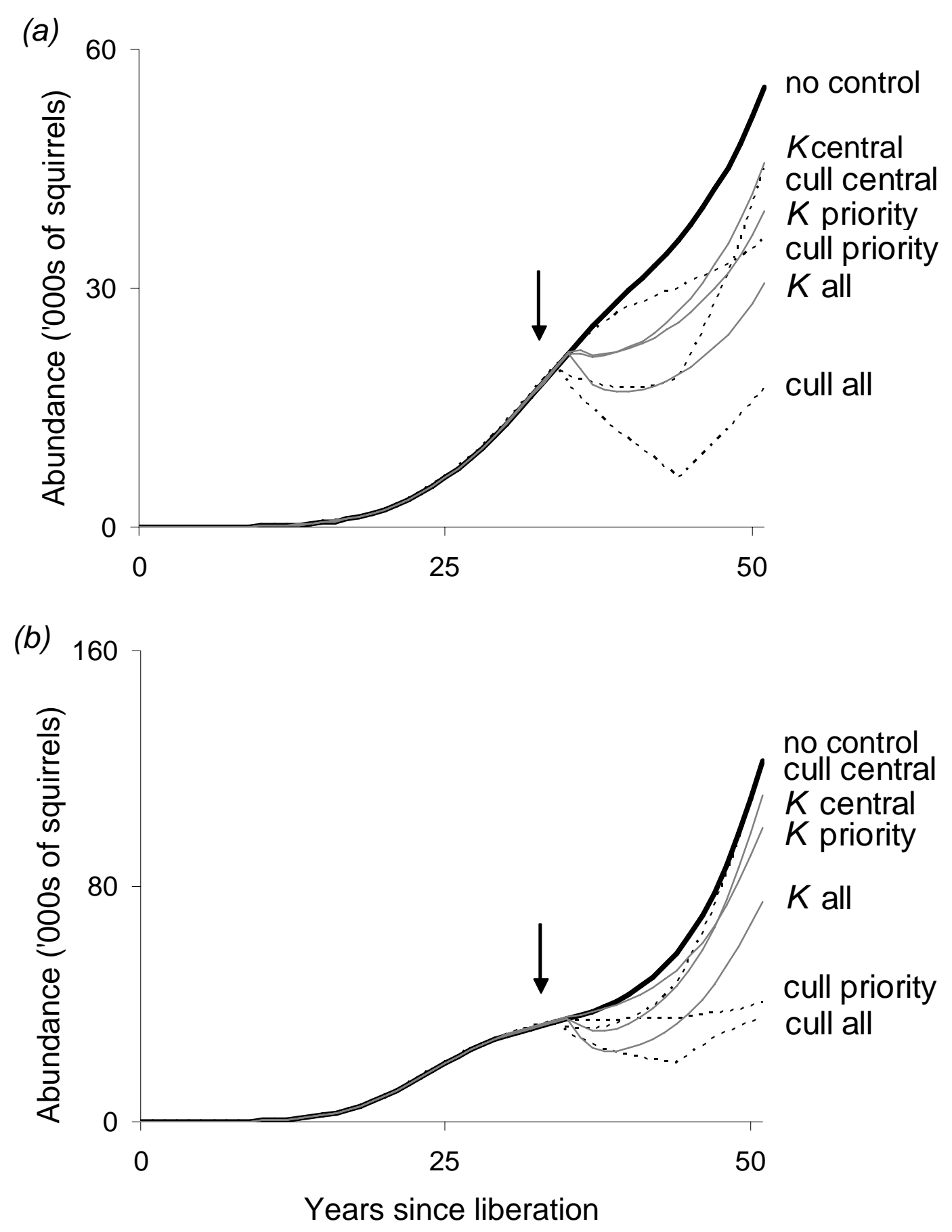